\title{
Genital Symptoms and Genital Hsv-2 and Hiv-1 Shedding In Co-Infected Women - Chiang Rai, Thailand
}

\author{
Brooke E Hoots ${ }^{1,2, *}$, Janet McNicholl ${ }^{3}$, Sara Whitehead ${ }^{4,5}$,Thomas A Peterman ${ }^{1}$, Lauri Markowitz ${ }^{1}$, Wan- \\ na Leelawiwat ${ }^{5}$, Tammy Evans-Strickfaden ${ }^{3}$, Cheng Chen ${ }^{1}$, Eileen F Dunne ${ }^{1}$
}

${ }^{1}$ Division of STD Prevention, Centers for Disease Control and Prevention, Atlanta, GA, USA

${ }^{2}$ Division of Applied Sciences, Epidemic Intelligence Service, Scientific Education and Professional Development

Program Office, Centers for Disease Control and Prevention, Atlanta, GA, USA

${ }^{3}$ Division of HIV/AIDS Prevention, Centers for Disease Control and Prevention, Atlanta, GA, USA

${ }^{4}$ Division of Tuberculosis Elimination, Centers for Disease Control and Prevention, Atlanta, GA, USA

${ }^{5}$ Thailand Ministry of Public Health-US CDC Collaboration, Nonthaburi, Thailand

${ }^{*}$ Corresponding author: Brooke Hoots, Centers for Disease Control and Prevention, 1600 Clifton Road NE, Mailstop E-46, Atlanta, GA 30329, E-mail: bhoots@cdc.gov

Received Date: April 02 2015, Accepted Date: August 25 2015, Published Date: August 282015

Citation: Brooke E Hoots, et al. (2015) Genital Symptoms and Genital Hsv-2 and Hiv-1 Shedding In Co-Infected Women Chiang Rai, Thailand. J HIV AIDS Infect Dis 2: 1-7.

\begin{abstract}
Objectives: To examine the association between genital symptoms and HSV-2 and HIV-1 genital shedding to better understand the natural history of mucosal events during co-infection.

Methods: As part of a randomized, crossover placebo-controlled trial of the effect of acyclovir on HIV-1 shedding in 67 Thai women co-infected with HIV-1 and HSV-2, we evaluated genital sores and symptoms self-reported on daily diary cards and their relationship to HSV-2 and HIV-1 genital shedding. Self-collected genital swabs collected during women's placebo month of the trial were used for analysis of HSV-2 and HIV-1 shedding.

Results: Of 561swabs tested for HSV-2 DNA, 27\% had detectable virus and of 525 swabs tested for HIV-1 RNA, 71\% had detectable virus. Most shedding occurred in the absence of sores or symptoms (77\% of swabs with detectable HSV-2 and $86 \%$ of swabs with detectable HIV-1). However, compared to swabs from women with no symptoms or sores, swabs from women with symptoms in the three-day window before collection were 2.0 (95\% CI: 1.2-3.3) times as likely to be positive for HSV-2 DNA, and swabs from women with sores were 2.7 (95\% CI: 1.6-4.4) times as likely to be positive.

Conclusions: Neither symptoms nor sores reported in a three-day window prior to swab collection were associated with HIV shedding. While HSV-2 shedding was more likely to occur in the presence of symptoms and sores, HIV-1 shedding was not. However, our study supports previous findings that most HSV-2 and HIV-1 genital shedding occurs during the larger number of days when there are no clinical symptoms.
\end{abstract}

Keywords: HSV-2; HIV; Shedding; Genital sores; Symptoms; Thailand

\section{Introduction}

Herpes simplex type 2 (HSV-2) infection is associated with increased HIV-1 infectiousness and transmission [1]. At the mucosal level, HSV-2 might increase the risk of HIV transmission due to genital vesicles and ulcers, and shedding of HIV through these breaches in epithelial integrity [2]. Increased risk of HIV-1 transmission might also be the result of increased HIV replication and shedding mediated by cytokine production and co-infection of HIV-infected cells

C2014 The Authors. Published by the JScholar under the terms of the Creative Commons Attribution License http://creativecommons.org/licenses/ by/3.0/, which permits unrestricted use, provided the original author and source are credited.
[3-5]. Epidemiological studies link acute episodes of genital ulcer disease to temporal increases in HIV plasma viral load [6]. However, a trial of HSV suppressive therapy given to HIV/HSV-2 co-infected persons in discordant partnerships found no effect on HIV transmission to the HIV-negative partners [7].

Studies demonstrating increased HIV-1 transmission in the presence of HSV-2 infection have been primarily conducted in persons with genital ulcers who comprise a small proportion of all persons with HSV-2 infection. There are few studies examining HIV shedding during asymptomatic HSV-2 infection or in the presence of genital symptoms other than 
ulcers. Furthermore, despite evidence of increased HIV-1 transmission in the presence of HSV-2, a trial of HSV suppressive therapy in HIV-positive women did not significantly reduce HIV transmission despite demonstrable reductions in HIV shedding [7]. Given these disappointing clinical trial results and the limited understanding of the relationship between HIV mucosal shedding and symptoms, more information is needed on the natural history of HSV-2 and HIV mucosal shedding.

To determine the relationship between symptoms and shedding of HSV-2 and HIV-1, we analyzed data from a study in Thailand in which women with HSV-2 and HIV-1 co-infection recorded their symptoms and collected vaginal swabs daily for one month.

\section{Methods}

\section{Study population and procedure}

The original study enrolled 67 women co-infected with HSV-2 and HIV-1 (hereafter referred to as "HIV") in a randomized, placebo-controlled crossover clinical trial of suppressive acyclovir in Chiang Rai, Thailand [8]. Eligible women were aged 18-49 years, had regular or no menses, had serum antibodies to HSV-2 and HIV, and were not eligible for antiretroviral therapy by Thai national guidelines at the time (CD4 count $<200$ cells/mL with opportunistic infection). Participants were randomized to a blinded study sequence of either acyclovir or placebo in the first month, a washout period in the second month (no product), and placebo or acyclovir (other product) in the third month. The study protocol was reviewed and approved by the Thailand Ministry of Public Health and the Institutional Review Board of the Centers for Disease Control and Prevention. The trial was registered in the National Institutes of Health clinical trials database (http://www.clinicaltrials.gov, NCT00362596). For this analysis, we evaluated women in the placebo month of the clinical trial.

Participants submitted daily self-collected vaginal swabs and daily diary cards during the intervention and placebo months of the study. Swab collection began the day after menstrual bleeding stopped and ended when the next period began, or after 28 days for women with no menses. Participants were taught how to use a single Dacron swab to swab the vaginal area (approximately two inches into the vaginal vault), the vulvar area, and the perianal region, for a total of 15 seconds. Participants inserted the swabs into a labeled tube containing a sponge impregnated with $150 \mu \mathrm{L}$ of AssayAssureTM ${ }^{\circledR}$ (Thermo Fisher Scientific, Waltham, MA, USA) that included a DNA/ RNA preservation solution. Tubes were placed into a cooler with frozen ice packs changed twice daily and temperature monitoring strips (3M Monitor Mark, Cold Chain Technologies, Holliston, MA, USA) and brought to weekly study visits. Swabs were then stored at $-70^{\circ} \mathrm{C}$ and shipped frozen to the laboratory for evaluation.

Participants also completed diary cards at the time of swab collection. Cards included questions about symptoms and behaviors (sexual intercourse, condom use, pill adherence, and exchange of ice packs). Symptoms were recorded as presence of burning, itching, tingling, and/or pain (collectively) at five possible sites/events (vagina/vulva, anus/perianal area, when urinating, thighs/buttocks, and other). Presence and location of sores on genitals were also recorded. Participants were not provided specific teaching on HSV-2 signs and symptoms. Diary cards were reviewed for completeness by study staff at weekly visits. Once each month, women were tested and treated for reproductive tract infections (chlamydia, gonorrhea, bacterial vaginosis, Trichomonas vaginalis, and Candida albicans) and pregnancy. A plasma specimen was collected for HIV-1 viral load at screening and halfway through the study.

\section{Laboratory methods}

Genital swab specimens were thawed and the sponge and swab were squeezed to release all fluid. Next, $600 \mu \mathrm{L}$ of Amplicor Monitor kit lysis buffer was added to $150 \mu \mathrm{L}$ of the fluid from each swab; this $750 \mu \mathrm{L}$ of eluate was used for nucleic acid extraction of both HIV-1 RNA and HSV-2 DNA [9]. Nucleic acid extraction procedures were modified by adding freshly prepared dithiothreitol (DTT) to $750 \mu \mathrm{L}$ of sample eluate to obtain a final concentration of $0.3 \mathrm{mM}$. The sample was heated at $60^{\circ} \mathrm{C}$ for 10 minutes. The remaining extraction steps followed the manufacturer's instructions. Specimens with detectable HIV and HSV-2 were also evaluated for quantity of virus reported as copies/swab. HIV RNA was quantified using Amplicor HIV-1 Monitor version 1.5 (Roche Molecular Systems, Inc., Branchburg, NJ, USA), with a lower limit of detection of 40 copies/swab and lower limit of quantification of 80 copies/ swab. HSV-2 DNA was quantified using an in-house TaqManbased real-time duplex polymerase chain reaction (PCR) assay described previously[9]. The lower limit of detection was 40 copies/swab and the lower limit of quantification was 400 copies/swab.

We analyzed viral shedding results from a subset of swabs that included those collected on study visit days 7,14 , and 21 , plus a random selection of 1-2 additional swabs per week during the placebo month. Swabs were therefore not consecutive and were not chosen based on report of symptoms or sores.

\section{Statistical analysis}

Shedding from swabs was first defined as a binary outcome (detectable or non-detectable). The exposures of interest were symptoms (burning itching, tingling, and/or pain at a genital site) and/or sores. The exposure variable was categorized as no symptoms or sores, symptoms only, sores only, and symptoms and sores in order to assess the associations between symptoms and shedding, and sores and shedding. Three different time intervals were used to define the presence or absence of symptoms and sores: the day of swab collection, a three-day window (the day of swab collection plus the two preceding days), and a seven-day window (the day of swab collection plus the six days preceding days).

Associations between shedding and patient characteristics were evaluated using binomial regression with generalized estimating equations with an exchangeable correlation matrix to account for non-independence of swabs collected from the same woman. Patient characteristics were phase of menstrual cycle, CD4 count (cells $/ \mu \mathrm{L})$, baseline HIV plasma viral load $\left(\log _{10}\right.$ copies $\left./ \mathrm{mL}\right)$, age, prior knowledge of HSV-2 diagnosis 
before enrollment, baseline history of HSV-2 symptoms, and other sexually transmitted or genital infections during the placebo month. Phase of menstrual cycle was categorized as periovulatory (estimated day of ovulation \pm 3 days), luteal (end of periovulatory phase to onset of menses), or follicular (end of menses to beginning of periovulatory phase) based on the estimated cycle day as previously described [10].Women without menses and those on hormonal contraceptives were excluded from bivariate analysis. CD4 count was measured twice during the study period and the value closest to the placebo month was used. Baseline HIV plasma viral load was $\log 10$-transformed to improve the assumption of normality of continuous variables.

Separate binomial regression models were used to evaluate the associations between symptoms and sores and dichotomous variables for 1) HSV-2 shedding and 2) HIV shedding. Effect modification was assessed first by creating an interaction term between the exposure and potential modifier. If the interaction term had a Wald $\mathrm{P}$ value $<.05$, it was retained in the model. Variables were considered potential confounders if they were related to both the exposure and the outcome and were not effect modifiers. The model was reduced using a backwards elimination strategy. Starting with the variable with the highest Wald $\mathrm{P}$ value, variables were removed from the model if the estimated prevalence ratio between symptoms/sores and shedding changed by less than $10 \%$ from the unadjusted association [11].

The quantity of virus shed was analyzed using binomial regression models. Due to small sample size, the exposure was collapsed to no symptoms or sores, symptoms only, and sores with or without symptoms. Due to left-censored data, quantity of shedding was categorized into four groups based on distribution, and models were restricted to two-category comparisons. Model building proceeded in the manner described above.

All analyses were done using SAS v9.3 (SAS Institute Inc., Cary, NC, USA).

\section{Results}

Participants had a median age of 33 years (Table 1). Their median time since HIV diagnosis was 5 years, median CD4 count was 366 cells/uL, and median plasma viral load was $4.6 \log$ copies/mL. Before enrollment, 17 (25\%) participants knew they had genital herpes, mostly due to symptoms or notification by their healthcare provider. Among these, the median time since they knew they had genital herpes was 3 years. Most participants $(60 \%)$ reported ever having symptoms consistent with genital herpes before enrollment. The most common symptoms were genital itching or tingling (95\%) and genital sores (85\%). Most symptoms were vaginal (90\%), but $20 \%$ reported symptoms at more than one site. While no women tested positive for chlamydia or gonorrhea during the placebo month, 8 (12\%) tested positive for bacterial vaginosis, 2 (3\%) for T. vaginalis, and 14 (21\%) for C. albicans.

Participants completed a median of 28 diary cards during the placebo month (range: 14-34). During the study, 20 (30\%) participants reported burning, itching, tingling, or pain in any area on at least one day and $23(35 \%)$ reported a sore on any area on at least one day during the month. The vagina/vulva
Table 1: Baseline characteristics of $67 \mathrm{HIV}-1 / \mathrm{HSV}-2$ co-infected women, Chiang Rai, Thailand

\begin{tabular}{|c|c|}
\hline Characteristic & \begin{tabular}{|l} 
Median (range) or n \\
$(\%)^{\mathrm{a}}$
\end{tabular} \\
\hline Age (years) & $33(22-46)$ \\
\hline Years since HIV diagnosis & $5(1-15)$ \\
\hline CD4 count $($ cells $/ \mu \mathrm{L})$ & 366 (209-930) \\
\hline HIV-1 plasma viral load (log copies/mL) & $4.6(2.9-5.8)$ \\
\hline $\begin{array}{l}\text { Knew they had genital herpes before enroll- } \\
\text { ment }\end{array}$ & $17(25 \%)$ \\
\hline \multicolumn{2}{|l|}{ Knew they had genital herpes based on $(n=17)$} \\
\hline Symptoms & $13(77 \%)$ \\
\hline Told by a provider & $8(47 \%)$ \\
\hline Partner has herpes & $2(12 \%)$ \\
\hline Other & $4(24 \%)$ \\
\hline $\begin{array}{l}\text { Time since they knew they had genital herpes } \\
(\mathrm{n}=17)\end{array}$ & $\begin{array}{l}3 \text { years ( } 4 \text { months }-10 \\
\text { years) }\end{array}$ \\
\hline $\begin{array}{l}\text { Ever had symptoms consistent with genital } \\
\text { herpes }\end{array}$ & $40(60 \%)$ \\
\hline Time since last symptom $(\mathrm{n}=40)$ & 3 months (1-4 months) \\
\hline \multicolumn{2}{|l|}{ Symptom $(\mathrm{n}=40)$} \\
\hline Genital itching or tingling & $38(95 \%)$ \\
\hline Genital sore & $34(85 \%)$ \\
\hline Genital pain & $23(58 \%)$ \\
\hline Genital burning & $23(58 \%)$ \\
\hline More than one symptom & $35(88 \%)$ \\
\hline \multicolumn{2}{|l|}{ Site of symptom $(n=40)$} \\
\hline Vagina & $36(90 \%)$ \\
\hline Buttocks & $7(18 \%)$ \\
\hline Anal/perianal & $3(8 \%)$ \\
\hline Upper thighs & $3(8 \%)$ \\
\hline More than one site & $8(20 \%)$ \\
\hline
\end{tabular}

Abbreviations: HSV-2, herpes simplex virus type 2

a Percentages are out of 67 unless otherwise indicated in the 'Characteristic' column

Figure 1: Prevalence ratios and 95\% confidence intervals for HSV-2 shedding with 7-day, 3-day, and same-day windows for symptoms/ sores prior to swab collection

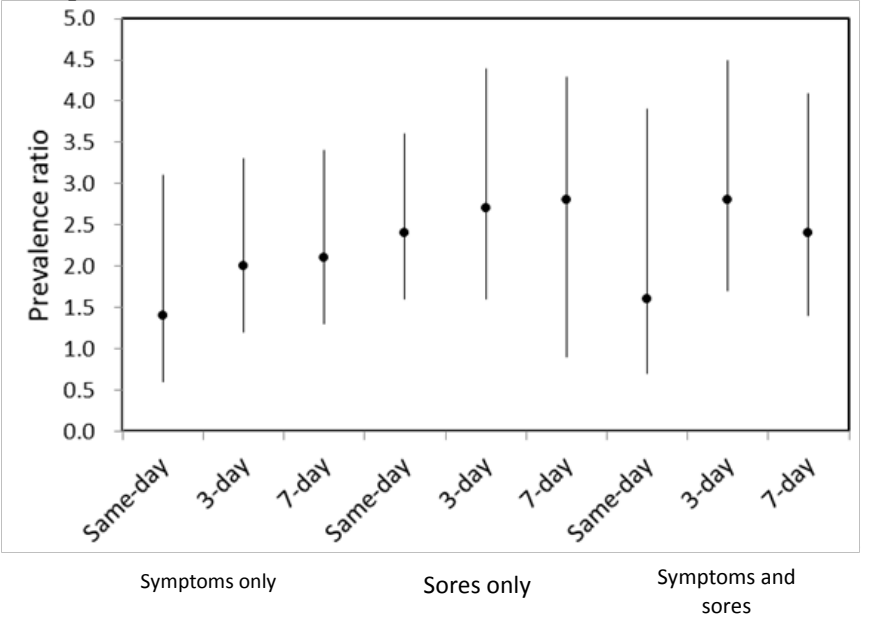

was the most common site of burning, itching, tingling, or pain $(12 / 20,60 \%)$ and of sores $(14 / 23,61 \%)$. There was no association between reporting symptoms before enrollment and reporting symptoms or sores during the placebo month. Similarly, there was no association between knowledge of having genital herpes before enrollment and reporting symptoms or sores during the placebo month (data not shown). 
Of the 576 swabs collected, 15 were excluded from the analysis of HSV-2 shedding: 11 were stored outside the required temperature range, three were collected while a woman was receiving episodic acyclovir, and one was analyzed using a different lab method. The remaining 561 swabs were used for the analysis of HSV-2 shedding (median of 9 swabs per woman, range: 1-12 swabs). For HIV shedding analysis, an additional 36 swabs had invalid HIV RNA results, leaving 525 swabs with valid HIV and HSV-2 results for analysis (median of 8 swabs per woman, range 1-9 swabs).

Of the 561swabs tested for HSV-2 DNA, 27\% had detectable virus. Three time windows were used to evaluate the association of symptoms and/or sores with HSV-2 shedding: sameday (day of swab collection), three-day, and seven-day windows. Comparing women with symptoms versus women with no symptoms or sores, the difference in shedding was less with a same-day window (35\% vs. $25 \%)$, than with a threeday window ( $44 \%$ vs. $23 \%$ ), or a seven-day window ( $47 \%$ vs. $21 \%$ ) (Figure1). Similar comparisons for sores only, and for symptoms plus sores, showed less difference in shedding with a same-day window compared to a three- or seven-day window. The three-day window period was used for the remaining analyses comparing symptoms and shedding events.

In bivariate analysis, HSV-2 shedding was significantly associated with higher baseline HIV plasma viral load and symptoms and/or sores in the three-day window prior to swab collection (Table 2), although most shedding was on days without symptoms or sores recorded prior to swab collection $(77 \%$; 114 of the 149 swabs shedding HSV-2). The sensitivity of symptoms alone for predicting shedding was $13 \%$, while the sensitivity of sores was $17 \%$. There were no associations between HSV-2 shedding and age, knowledge of genital herpes or symptoms of genital herpes before enrollment, CD4 count, or phase of menstrual cycle.

Of the 525 swabs tested for HIV RNA, 71\% had detectable virus. HIV shedding was significantly associated with higher baseline HIV plasma viral load and lower CD4 count. HIV shedding was not associated with age, knowledge of genital herpes or symptoms of genital herpes before enrollment, phase of menstrual cycle, or symptoms and/or sores. Most HIV shedding also occurred on days without symptoms or sores recorded prior to swab collection $(86 \% ; 320$ of 370 swabs shedding HIV). Neither HSV-2 nor HIV shedding were associated with having bacterial vaginosis or candida diagnosed during the placebo month (data not shown). The prevalence ratio for the association between HSV-2 shedding and HIV shedding on the same swab was 1.4 and not statistically significant $(\mathrm{P}=.06)$.

In multivariable analysis, only baseline HIV plasma viral load remained in the HSV-2 shedding model as a confounder of the relationship between symptoms and sores and HSV-2 shedding (Table 3). Compared to intervals when there were no symptoms or sores, swabs collected when women had symptoms in the three-day window prior were 2.0 times as likely to be positive for HSV-2 DNA; this association was stronger when women had sores alone, at 2.7 (95\% CI: 1.6-4.4) and when they had sores and symptoms (PR: 2.8, 95\% CI: 1.7-4.5).
Table 2: Characteristics associated with HSV-2 and HIV-1 sheddinga on genital swabs self-collected from 67 women during the placebo month, Chiang Rai, Thailand.

\begin{tabular}{|l|l|l|l|l|l|l|l|l|}
\hline & \multicolumn{3}{|l|}{ HSV-2 shedding $(\mathrm{N}=561)$} & \multicolumn{3}{l|}{ HIV-1 shedding $(\mathrm{N}=525)$} \\
\hline $\begin{array}{l}\text { Character- } \\
\text { istic }\end{array}$ & $\mathrm{n}(\%)$ & \multicolumn{2}{|l|}{$\mathrm{PR}^{\mathrm{b}}(95 \% \mathrm{CI})$} & \multicolumn{2}{l|}{$\mathrm{n}(\%)$} & \multicolumn{2}{l|}{$\mathrm{PR}^{\mathrm{b}}(95 \% \mathrm{CI})$} \\
\hline Overall & 149 & -26.6 & & & 370 & -70.5 & & \\
\hline
\end{tabular}

Baseline characteristics

\section{Age group (years)}

\begin{tabular}{|l|l|l|l|l|l|l|l|l|}
\hline $22-30$ & 19 & -18.8 & 1 & (ref) & 66 & -68 & 1 & (ref) \\
\hline $30-39$ & 94 & -28.1 & 1.5 & $(0.7-3.3)$ & 220 & -69.6 & 1 & $(0.8-1.3)$ \\
\hline $40-46$ & 36 & -28.8 & 1.5 & $(0.6-3.6)$ & 84 & -75 & 1.1 & $(0.8-1.5)$ \\
\hline
\end{tabular}

Baseline HIV-1 plasma viral load

\section{$\left(\log _{10}\right.$ copies $\left./ \mathrm{mL}\right)$}

\begin{tabular}{|l|l|l|l|l|l|l|l|l|}
\hline$\leq 4.0$ & 16 & -11 & 1 & $($ ref $)$ & 42 & -30.7 & 1 & $($ ref $)$ \\
\hline $4.0-5.0$ & 88 & -31.7 & 2.5 & $(1.2-5.0)^{c}$ & 206 & -78.9 & 2.3 & $(1.6-3.5)^{c}$ \\
\hline$>5.0$ & 45 & -32.9 & 2.3 & $(1.0-5.2)^{c}$ & 122 & -96.1 & 2.9 & $(1.9-4.2)^{c}$ \\
\hline
\end{tabular}

\begin{tabular}{|l|l|l|l|l|}
\hline$>5.0$ & 45 & -32.9 & 2.3 & $(1.0-5.2)$ \\
\hline
\end{tabular}

\begin{tabular}{|l|l|l|l|l|l|l|l|l|}
\hline No & 113 & -27.2 & 1 & (ref) & 273 & -69.8 & 1 & (ref) \\
\hline Yes & 36 & -24.7 & 0.9 & $(0.5-1.6)$ & 97 & -72.4 & 1 & $(0.8-1.3)$ \\
\hline
\end{tabular}

Ever had symptoms consistent with genital herpes

\begin{tabular}{|l|l|l|l|l|l|l|l|l|}
\hline No & 62 & -27.1 & 1 & $(\mathrm{ref})$ & 161 & -73.5 & 1 & (ref) \\
\hline Yes & 87 & -26.2 & 1 & $(0.6-1.7)$ & 209 & -68.3 & 1 & $(0.8-1.2)$ \\
\hline
\end{tabular}

Placebo month characteristics

\section{CD4 count $(\text { cells } / \mu \mathrm{L})^{\mathrm{d}}$}

\begin{tabular}{|l|l|l|l|l|l|l|l|l|}
\hline $209-350$ & 71 & -25 & 1 & $($ ref $)$ & 216 & -81.8 & 1 & (ref) \\
\hline $351-500$ & 65 & -38.7 & 1.5 & $(0.9-2.6)$ & 107 & -67.7 & 0.8 & $(0.7-1.0)^{c}$ \\
\hline $501-930$ & 13 & -11.9 & 0.5 & $(0.3-1.0)$ & 47 & -45.6 & 0.6 & $(0.4-0.9)^{c}$ \\
\hline
\end{tabular}

Phase of menstrual cycle ${ }^{e}$

\begin{tabular}{|l|l|l|l|l|l|l|l|l|}
\hline Follicular & 29 & -27.6 & 1 & (ref) & 81 & -77.1 & 1 & (ref) \\
\hline
\end{tabular}

\begin{tabular}{|l|l|l|l|l|l|l|l|l|}
\hline Periovulatory & 39 & -22.9 & 0.8 & $(0.5-1.2)$ & 118 & -69.4 & 0.9 & $(0.8-1.0)$ \\
\hline
\end{tabular}

\begin{tabular}{|l|l|l|l|l|l|l|l|l|}
\hline Luteal & 51 & -24.6 & 0.8 & $(0.5-1.3)$ & 144 & -69.6 & 0.9 & $(0.8-1.0)$ \\
\hline
\end{tabular}

\begin{tabular}{|l|l|l|l|l|l|l|l|l|}
\hline $\begin{array}{l}\text { HIV shed- } \\
\text { ding }^{\text {a }}\end{array}$ & & & & & & & & \\
\hline No & 25 & -16.1 & 1 & (ref) & -- & & -- & \\
\hline Yes & 114 & -30.8 & 1.4 & $(1.0-1.9)$ & & & & \\
\hline
\end{tabular}

Symptoms and/or sores ${ }^{\mathrm{f}}$

\begin{tabular}{|l|l|l|l|l|l|l|l|l|}
\hline $\begin{array}{l}\text { No symp- } \\
\text { toms or sores }\end{array}$ & 114 & -22.9 & 1 & $(\mathrm{ref})$ & 320 & -69 & 1 & $(\mathrm{ref})$ \\
\hline $\begin{array}{l}\text { Symptoms } \\
\text { only }\end{array}$ & 10 & -43.5 & 2 & $(1.2-3.3)^{\mathrm{c}}$ & 21 & -91.3 & 1.3 & $(0.8-2.3)$ \\
\hline Sores only & 15 & -65.2 & 2.7 & $(1.6-4.4)^{\mathrm{c}}$ & 17 & -77.3 & 1.1 & $(0.6-2.1)$ \\
\hline $\begin{array}{l}\text { Symptoms } \\
\text { and sores }\end{array}$ & 10 & -62.5 & 2.8 & $(1.7-4.5)^{\mathrm{c}}$ & 12 & -75 & 0.8 & $(0.3-1.8)$ \\
\hline
\end{tabular}

Abbreviations: $\mathrm{CI}$, confidence interval; $\mathrm{HSV}-2$, herpes simplex virus type 2; PR, prevalence ratio; ref, referent

${ }^{a}$ Defined as binary outcomes, with non-detectable viral shedding considered no shedding and a non-quantifiable or quantifiable viral shedding considered shedding.

${ }^{\mathrm{b}}$ Prevalence Ratios (PR) are adjusted for multiple comparisons for each woman. ${ }^{c} \mathrm{P}<.05$

${ }^{\mathrm{d}} \mathrm{CD} 4$ count was measured twice during the study period; the value closest to the placebo month was used.

${ }^{\mathrm{e}}$ Categorized as follicular (4-19 days before ovulation), periovulatory ( 3 days before to 3 days after ovulation), or luteal (4-14 days after ovulation) based on the estimated cycle day; women without menses or on hormonal contraceptives were excluded $(n=38), n=43$ missing menstrual cycle phase.

${ }_{\mathrm{f}}^{\mathrm{f}}$ Defined as presence of prodromal symptoms and/or sores on diary cards in the two days prior to and day of swabs collection (three-day window before swabs collection). Symptoms were defined as burning, itching, tingling, or pain at any site/event (vagina/vulva, anus/ perianal area, when urinating, thighs/buttocks, or other); sore was defined as sore at any site (vagina/vulva, anus, buttocks, thighs, or other). Symptoms and/or sores categories are mutually exclusive.

In the HIV shedding model, baseline HIV plasma viral load was again the only confounder to remain in the model. HIV shedding was not associated with symptoms and/or sores in multivariable analysis.

Among 18 women who experienced both sores and no sores over the study period, we compared median HIV copies for swabs where a sore was reported to swabs where a sore was not 
Table 3: Adjusted ${ }^{a}$ prevalence ratios between symptoms and/or sores ${ }^{b}$ and HSV-2 and HIV-1 shedding on self-collected genital swabs, Chiang Rai, Thailand

\begin{tabular}{|c|c|c|c|c|}
\hline Variable & \multicolumn{2}{|c|}{ HSV- 2 shedding $(\mathrm{N}=561)$} & \multicolumn{2}{|c|}{ HIV shedding ${ }^{c}(\mathrm{~N}=525)$} \\
\hline & \multicolumn{2}{|c|}{$\mathrm{aPR}(95 \% \mathrm{CI})$} & \multicolumn{2}{|c|}{ aPR $(95 \%$ CI $)$} \\
\hline \multicolumn{5}{|c|}{ Symptoms and/or sores } \\
\hline $\begin{array}{l}\text { No symptoms, } \\
\text { no sores }\end{array}$ & 1 & (ref) & 1 & (ref) \\
\hline Symptoms only & 2 & $(1.2-3.3)^{\mathrm{d}}$ & 1.4 & $(0.6-3.2)$ \\
\hline Sores only & 2.7 & $(1.6-4.4)^{\mathrm{d}}$ & 1.1 & $(0.4-2.8)$ \\
\hline $\begin{array}{l}\text { Sores and } \\
\text { symptoms }\end{array}$ & 2.8 & $(1.7-4.5)^{\mathrm{d}}$ & 0.7 & $(0.3-2.2)$ \\
\hline $\begin{array}{l}\text { Baseline HIV-1 } \\
\text { plasma viral } \\
\text { load }\end{array}$ & 1.5 & $(1.1-2.1)^{\mathrm{d}}$ & 7.5 & $(4.2-13.1)^{\mathrm{d}}$ \\
\hline
\end{tabular}

Abbreviations: aPR, adjusted prevalence ratio; $\mathrm{CI}$, confidence interval; ref, referent a Adjusted for HIV plasma viral load

${ }^{\mathrm{b}}$ Defined as presence of prodromal symptoms and/or sores on diary cards in the two days prior to and day of swabs collection (three-day window before swabs collection). Symptoms were defined as burning, itching, tingling, or pain at any site/event (vagina/ vulva, anus/perianal area, when urinating, thighs/buttocks, or other); sore was defined as sore at any site (vagina/vulva, anus, buttocks, thighs, or other). Symptoms and/or sores categories are mutually exclusive.

c Defined as binary outcome, with non-detectable viral shedding considered no shedding and a non-quantifiable or quantifiable viral shedding considered shedding.

${ }^{\mathrm{d}} \mathrm{P}<.05$

reported in the three days prior to swab collection. The median was similar among those swabs with and without a sore reported in the three days prior to collection (data not shown).

\section{Discussion}

HSV-2 shedding was more likely when women reported symptoms in the three-day window preceding swab collection compared to when they had no preceding symptoms. However, symptoms and sores were rarely reported, so most HSV2 shedding occurred on days when there were no associated symptoms or sores. Neither symptoms nor sores were associated with HIV shedding.

This analysis is unique in that it examines both symptoms and sores in HSV-2 and HIV co-infected women and their association with HIV shedding and HSV-2 shedding. Other studies have examined herpes and HIV shedding, but primarily among those with genital ulcer disease. A study in Burkina Faso used cervicovaginal lavage (CVL) specimens to compare women with versus without genital ulcer disease (GUD) [12]. In it, GUD was associated with HIV RNA detection and higher genital HIV RNA loads. It also found that GUD and HSV-2 genital shedding were associated with higher plasma HIV viral load. A study similar to ours examined HSV-2 and HIV coinfected women in Tanzania, and reported the prevalence of detectable HIV did not differ between women-visits with clinical herpes and subclinical herpes (visits without lesions) [13]. While the quantity of genital HIV RNA was higher in women with herpetic lesions, the association was not statistically significant in multivariable analysis. Both this study and ours suggest that HIV transmission is unlikely to be influenced by HSV-2 symptoms.

Studies examining symptoms and HSV-2 shedding are difficult to compare because they have used varying definitions of symptoms. Several studies have defined symptomatic HSV-2 infection as a history of symptomatic genital herpes before the serologic diagnosis of HSV-2 [14,15]. While those studies found that symptomatic HSV-2 infection was associated with more frequent HSV-2 shedding, we found no association between history of symptoms consistent with genital herpes before enrollment or knowledge of genital herpes status before enrollment and HSV-2 shedding. A study by Fife et al had a similar design to this study in which participants recorded symptoms on diary cards and swabs were collected to evaluate HSV-2 shedding. [16]. Their analysis of symptoms, however, used a three-day window around the time of swab collection that included days before and after swab collection. Self-report of vaginal pain was associated with detection of HSV-2, while vaginal discharge was not.

Our study has several strengths and limitations. Daily diary cards allowed us to examine more detailed symptoms and their relationship to shedding events. The study design also allowed symptoms to be matched to time of swab collection and to examine window periods for symptoms and sores preceding shedding events. A limitation of this study is that it enrolled Thai women co-infected with HSV-2 and HIV who were not eligible for antiretroviral therapy (CD4 count $>200$ cells $/ \mathrm{mL}$ ) and therefore may not be generalizable to other co-infected women. In addition, our genital swabs specimen collection method (combined vaginal, vulvar, and perianal sampling) prevented examining HIV shedding by particular site, so we cannot exclude the possibility that HIV shedding may be increased at one site. The Amplicor-based swab testing may detect both HIV proviral DNA and RNA, which may have resulted in increased prevalence of detection. Also, symptoms and sores were self-reported and not based on provider evaluation or examination; women were not educated on symptoms and sores and may have confused symptoms for sores or vice versa. As there were few reports of symptoms and sores (i.e., only 23 women (34\%) with 62 episodes of symptoms and/or sores preceding a swab), the evaluation may have been underpowered to detect an association of symptoms to HIV shedding, if one exists. Reported symptoms were non-specific and had low sensitivity and could be due to other factors besides HSV infection, although we did observe associations between symptoms and HSV shedding.

Examination of both HSV-2 and HIV shedding from selfcollected genital swabs provides insight on the relationship between symptoms and viral shedding. Our study, like previous studies, found HSV shedding was more common on days following symptoms compared to days when there were no symptoms or sores. However, HIV shedding occurred on most days, and was unrelated to symptoms.

Sources of support: Supported by Centers for Disease Control and Prevention

Disclaimer: The findings and conclusions in this report are those of the authors and do not necessarily represent the views of the Centers for Disease Control and Prevention.

\section{Key Messages}

- Most HSV-2 DNA and HIV-1 RNA genital shedding occurred in the absence of sores or symptoms. 
- Compared to swabs from women without symptoms, swabs from women with symptoms before collection were twice as likely to be positive for HSV-2 DNA.

- Neither symptoms nor sores reported in a three-day window prior to swab collection were associated with HIV shedding.

\section{References}

1) Gray RH, Wawer MJ, Brookmeyer R, Sewankambo NK, Serwadda D, et al. (2001) Probability of HIV-1 transmission per coital act in monogamous, heterosexual, HIV-1-discordant couples in Rakai, Uganda. Lancet 357: 1149-1153.

2) Grosskurth H, Gray R, Hayes R, Mabey D, Wawer M (2000) Control of sexually transmitted diseases for HIV-1 prevention: understanding the implications of the Mwanza and Rakai trials. Lancet 355:1981-1987.

3) Moriuchi H, Moriuchi M (2000) In vitro induction of HIV-1 replication in resting CD4(+) T cells derived from individuals with undetectable plasma viremia upon stimulation with human T-cell leukemia virus type I. Virology 278:514-519.

4) Kucera LS, Leake E, Iyer N, Raben D, Myrvik QN (1990) Human immunodeficiency virus type 1 (HIV-1) and herpes simplex virus type 2 (HSV-2) can coinfect and simultaneously replicate in the same human CD4+ cell: effect of coinfection on infectious HSV-2 and HIV-1 replication. AIDS Res Hum Retroviruses 6:641-647.

5) Heng MC, Heng SY, Allen SG (1994) Co-infection and synergy of human immunodeficiency virus- 1 and herpes simplex virus-1.Lancet 343:255-258.

6) Mole L, Ripich S, Margolis D, Holodniy M (1997) The impact of active herpes simplex virus infection on human immunodeficiency virus load. J Infect Dis 176:766-770.

7) Celum C, Wald A, Lingappa JR, Magaret AS, Wang RS, et al. (2010) Acyclovir and transmission of HIV-1 from persons infected with HIV-1 and HSV-2. N Engl J Med 362: 427-439.

8) Dunne EF, Whitehead S, Sternberg M, Thepamnuay S, Leelawiwat W, et al. (2008) Suppressive acyclovir therapy reduces HIV cervicovaginal shedding in HIV- and HSV-2-infected women, Chiang Rai, Thailand. J Acquir Immune Defic Syndr 49:77-83.

9) Forhan SE, Dunne EF, Sternberg MR, Whitehead SJ, Leelawiwat W, et al. (2012) HIV-1 and herpes simplex virus type-2 genital shedding among co-infected women using self-collected swabs in Chiang Rai, Thailand. Int J STD AIDS 23:560-564.

10) Curlin ME, Leelawiwat W, Dunne EF, Chonwattana W, Mock PA, et al. (2013) Cyclic changes in HIV shedding from the female genital tract during the menstrual cycle. J Infect Dis 207:1616-1620.

11) Maldonado G, Greenland S (1993) Simulation study of confounder-selection strategies. Am J Epidemiol 138:923-936.

12) Nagot N, Ouedraogo A, Konate I, Weiss HA, Foulongne V, et al. (2008 Roles of clinical and subclinical reactivated herpes simplex virus type 2 infection and human immunodeficiency virus type 1 (HIV-1)-induced immunosuppression on genital and plasma HIV-1 levels. J Infect Dis 198:241-249.

13) Todd J, Riedner G, Maboko L, Hoelscher M, Weiss HA, et al. (2013) Effect of genital herpes on cervicovaginal HIV shedding in women co-infected with HIV AND HSV-2 in Tanzania. PLoS One 8:e59037.

14) Tronstein E, Johnston C, Huang ML, Selke S, Magaret A, et al. (2011) Genital shedding of herpes simplex virus among symptomatic and asymptomatic persons with HSV-2 infection. JAMA 305:14411449.
15) Wald A, Zeh J, Selke S, Warren T, Ryncarz AJ (2000) Reactivation of genital herpes simplex virus type 2 infection in asymptomatic seropositive persons. N Engl J Med 342:844-850.

16) Fife KH, Williams JA, Thomas AL, Ofner S, Katz BP, et al. (2010) Herpes simplex virus type 2 infection in young adult women: risk factors for infection and frequency of viral shedding. Sex Transm Dis $37: 248-252$

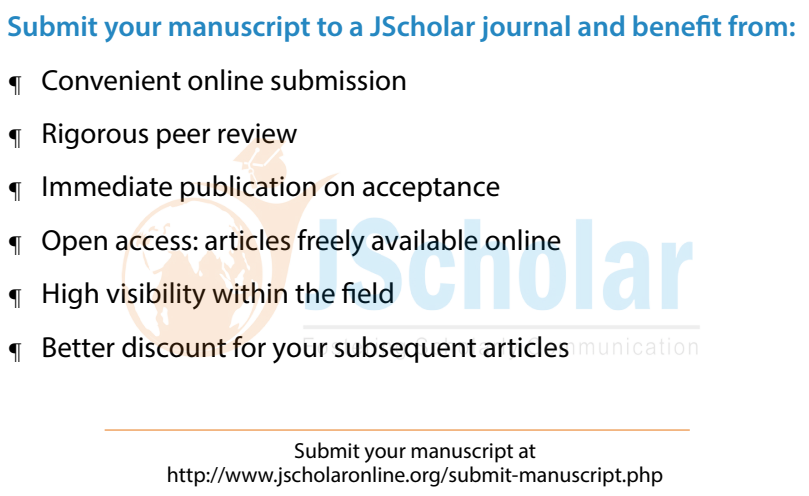

